\title{
Endometrial Stromal Nödül
}

\author{
Endometrial Stromal Nodule
}

Yasemin Yuyucu Karabulut ${ }^{1}$, Ayșe Sertçelik ${ }^{1}$

Endometrial stromal nodül (ESN), endometrial stromal tümörlerin benign ucunu olusturur. Tipik olarak düzgün sınırlı, kapsül bulundurmayan 0.5 ile 22 (ortalama 7) $\mathrm{cm}$ boyutlarında olabilen benign stromal nodüllerdir. Endometrial yerleșimde polipoid olan nodüller myometrial veya subserozal yerleșim de gösterebilir. Myometriuma invazyon olusturmaması en belirleyici mikroskopik özelliklerindendir. Oldukça nadir görülen bu antite özellikle küretaj materyallerinde düșük gradeli endometrial stromal sarkom (ESS) ile ayırıcı tanısı mümkün olmamaktadır. 64 yașında, postmenapozal kanama ve pelvik ağrı șikayetleri ile bașvuran hastanın küretaj materyalinde izlenen morfolojik bulgular nedeniyle yüksek gradeli malign tümör olarak raporlanmıș, daha sonra gönderilen histerektomi materyalinin incelenmesinde myometriuma invazyon görülmemiș ve olgu endometrial stromal nodül olarak raporlanmıștır.

Anahtar Sözcükler: Endometrial Stromal Tümörler, Miyometrium

Endometrial stromal nodule (ESN) represents the benign end of the spectrum within the category of endometrial stromal tumors. Typically well-cicumscribed but not encapsulated tumors ranging in size from 0.5 to 22 (mean 7) cm. If centered in endometrium, they are freguently polypoid; they may be intramyometrial or subserozal. On low- power examination, these tumors are well demarcated from the adjacent myometrium. The differentiation of ESN from low-grade endometrial stromal sarcoma is not possible in a curretage specimen. 64 years old patient 's curetage material who has postmenoposal bleeding and pain semptoms was examined and diagnosed as endometrial stromal sarcoma (ESS). But at histerectomy specimen we saw any invazion of myometrium and change the diagnose as ESN

Key Words: Endometrial Stromal Tumors, Myometrium

Endometrial stromal nodül (ESN), endometrial stromal sarkomun (ESS) benign ucunu oluşturur. Tipik olarak düzgün sinırlı, kapsül bulundurmayan ortalama $7 \mathrm{~cm}$ boyutlarında olabilen ancak $22 \mathrm{~cm}$ lere ulaşabilen benign stromal nodüllerdir (1). Sitolojik ve morfolojik özellikleri stromal hücrelere benzer (2). Endometrial stromal tümörler sinıflaması oldukça zor ve kompleks olan tümörler gurubudur (3). Dünya sağllk örgütünün son sınıflamasında uterin stromal tümörler üç guruba ayrılmıştır: benign endometrial stromal nodül (ESN), düşük dereceli endometrial stromal sarkom (LGESS) ve andiferansiye endometrial sarkom (UES) (4). ESN sitolojik olarak ESS' a benzer ancak düzgün sinırlara sahip olması ve myometriuma invazyon göstermemesi ile ESS'dan ayrilır ve klinik olarak benign olduğu düşünülür. UES ise çok nadir görülmekle birlikte oldukça maligndir ve tümör hücreleri endometrial stromal diferansiasyonunu kaybetmiştir (4). ESN'lerde klasik olarak endometrial yerleşimde polipoid olan nodüller myometrial veya subserozal yerleşim de gösterebilir. Sar1- beyaz renkli kesit yüzüne sahip olup, kanama, nekroz veya kistik değişiklikler izlenebilir. Myometriuma invazyon olusturmamas1 en belirleyici mikroskopik özelliklerindendir. Mikroskopik olarak hiper veya hiposellüler olabilen tümörde zemin mikzoid veya fibrotiktir, proliferatif faz endometrial stromay1 andiran bir morfolojiye sahiptir. $10 \mathrm{BBA}$ da $1-5$ mitoz izlenebilir.

\footnotetext{
Geliș tarihi: 30.04.2012 • Kabul tarihi: 13.02.2014

Iletișim

Dr. Yasemin Yuyucu Karabulut

Tel: 0 (0505) 6497196

E-posta: yykarabulut@yahoo.com.tr

Ankara Üniversitesi Tıp Fakültesi Tıbbi Patoloji Anabilim Dal

Samanpazarı/ANKARA
} 


\section{OLGU}

64 yaşında, postmenapozal kanama ve pelvik ağrı şikayetleri ile başvuran hastanın küretaj materyalinde kanama ve nekroz komşuluğunda net bir organizasyon göstermeyen, oval- iğsi șekilli, dar, soluk eozinofilik sitoplazmalı, bir kısmının nükleolü belirgin, büyük hiperkromatik nükleuslu hücrelerin olușturduğu tümöral gelişim izlenmiş (Şekil 1 AF), ve olgu bu morfolojik bulgular nedeniyle yüksek gradeli malign tümör olarak raporlanmıştır. Bu tanı üzerine gönderilen histerektomi materyalinin $2 \mathrm{~cm}$ uzunluğunda serviks, $5 \times 5 \times 3 \mathrm{~cm}$ boyutlarında korpus uteri bulundurduğu izlenmiş ve materyal serviksten açlarak incelendiğinde, endometrial kavite

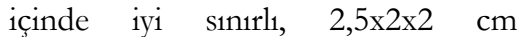
boyutlarında yüzeyi nekrotik, myometriyumla belirgin sinırlanma gösteren polipoid lezyon görülmüştür. Lezyon total takibe alınmış ve mikroskopik değerlendirmede myometriuma net ivazyon bulunmadığı izlenmiş, tümör hücrelerinin arterioller çevresinde yuvalanmalar oluşturduğu görülmüştür (Şekil 2 A-D). Küretaj materyalinde bahsedilen yüksek gradeli izlenimi veren alanların çok dar sahalarda bulunduğu ve aramalara rağmen sadece 2 mitoz bulundurduğu vasküler invazyon bulundurmadığ1 görülmüş̧tür. Ayırıcı tanı amaçlı olguda SMA, desmin, caldesmon, ER, PR, CD10 immümhistokimyasal boyamaları yapılmıştır. Desmin ile zayıf fokal, CD10 diffüz kuvvetli sitoplazmik (Șekil 3), ER (Şekil 4) ile nükleer boyanma izlenmiş, SMA ve caldesmon negatif bulunmuştur. Mevcut morfolojik ve immünhistokimyasal bulgular eşliğinde olgu ESN olarak raporlanmiştır.
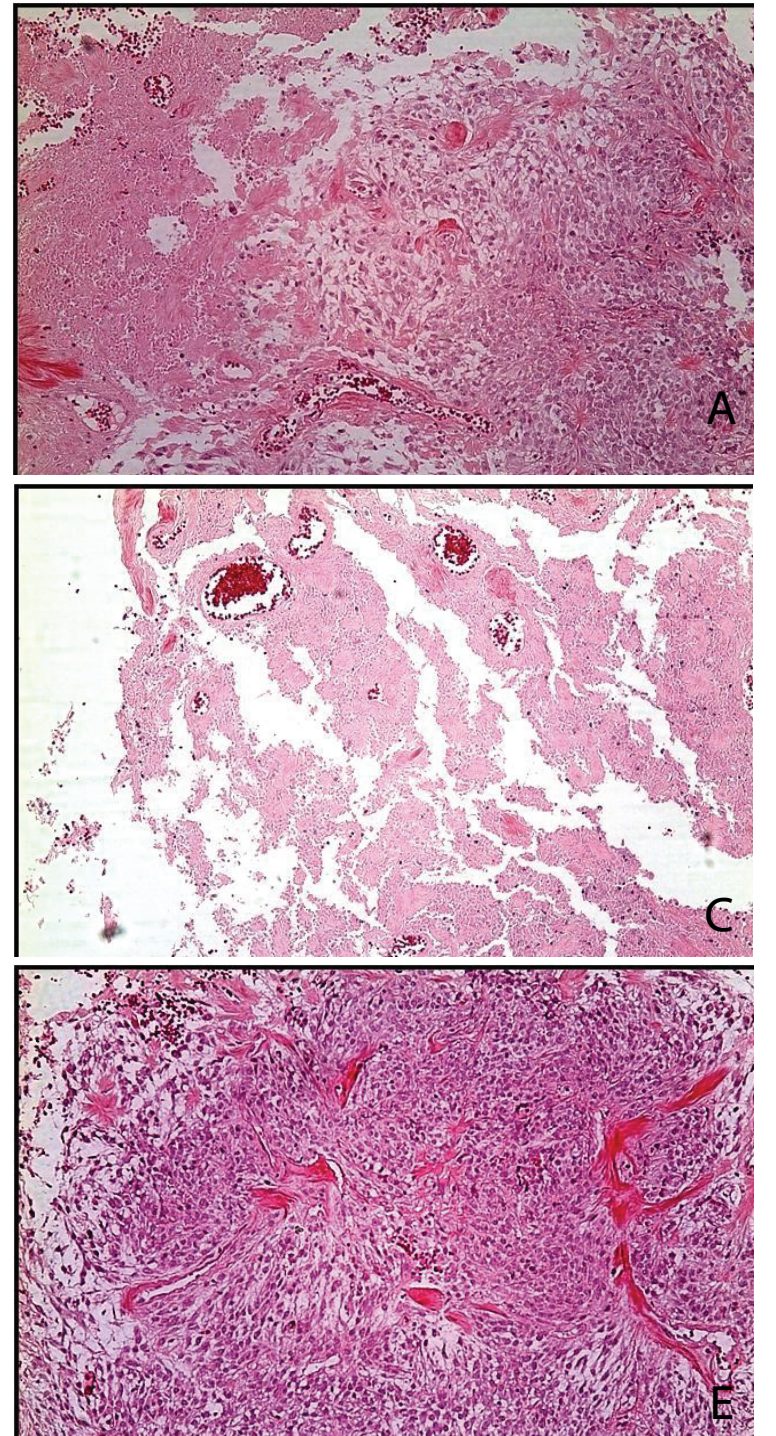
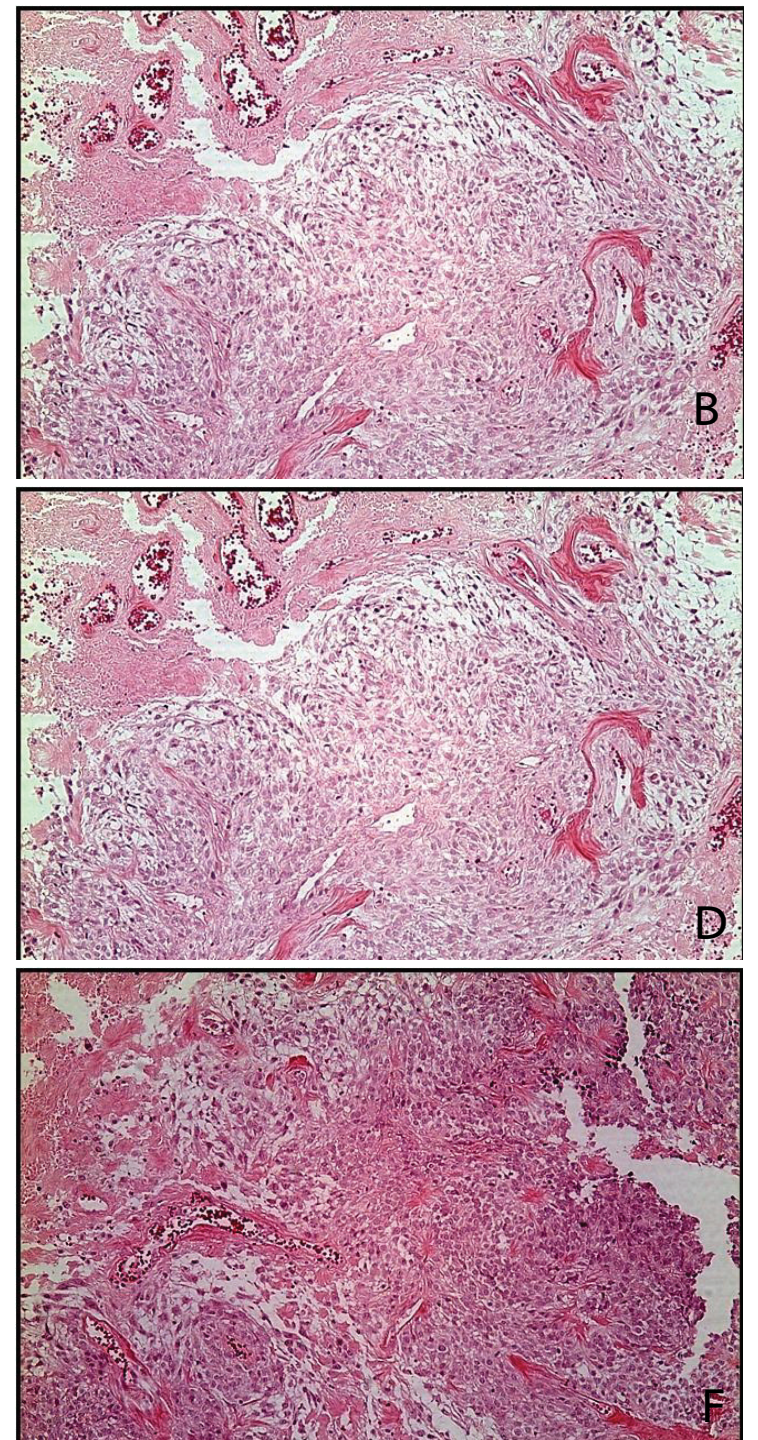

Şekil 1. A-F: Küretaj materyalinde yaygın kanama ve nekroz komşuluğunda net bir organizasyon göstermeyen, oval- iğsi şekilli, dar, soluk eozinofilik sitoplazmalı, nükleolü belirgin, büyük hiperkromatik nükleuslu hücrelerin oluşturduğu tümör (H\&E;A,C,D,Ex100), (H\&E;Bx40), (H\&E;Fx200). 

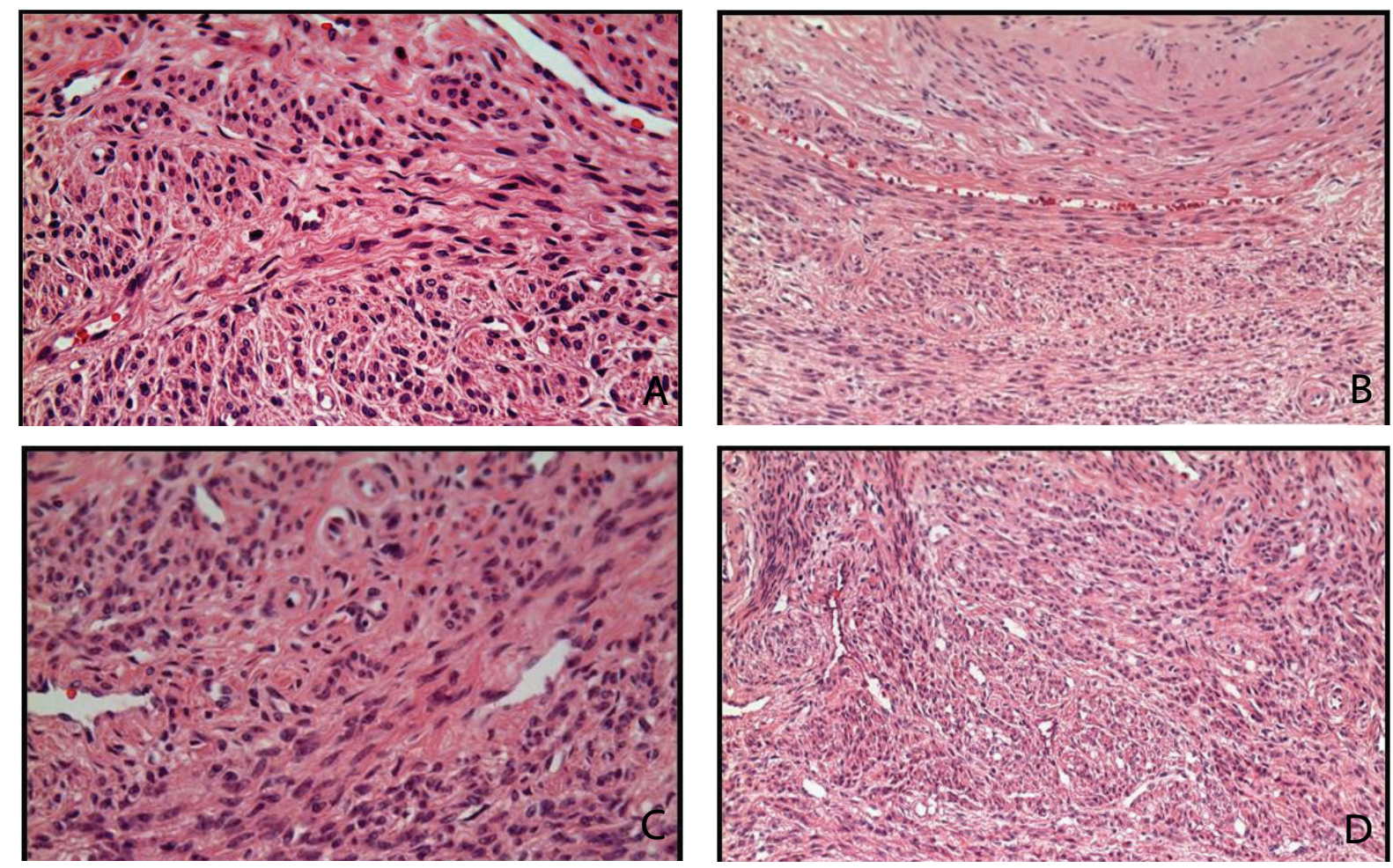

Şekil 2. A-D: Histerektomi materyaline ait resimlerde arterioller çevresinde yuvalanmalar oluşturan tümör hücreleri (H\&E; $A, C, D \times 100)$, (H\&E;Bx200).

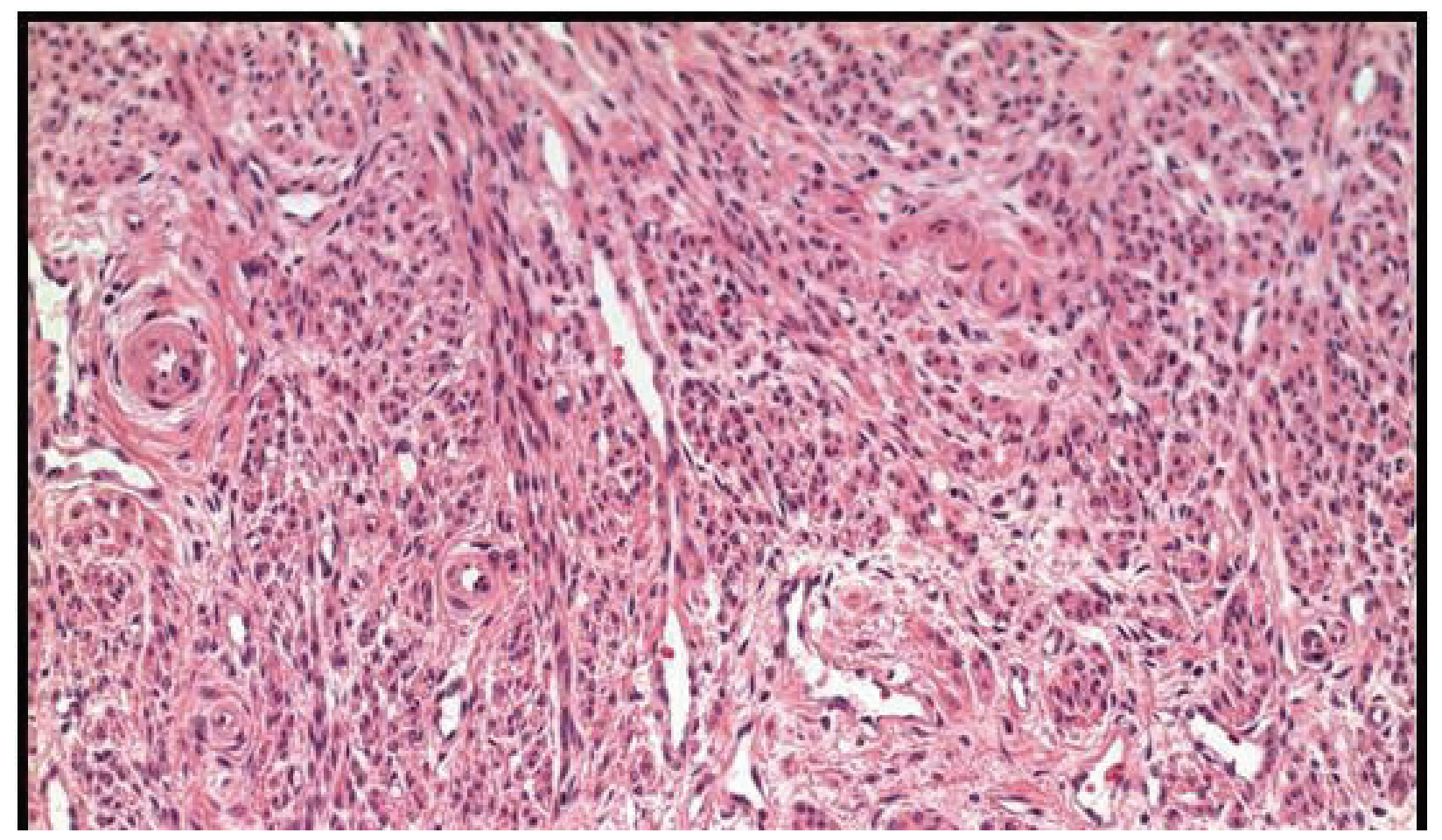

Şekil 3. CD10 ile tümör hücrelerinde diffüz kuvvetli sitoplazmik boyanma (CD10; x100). 


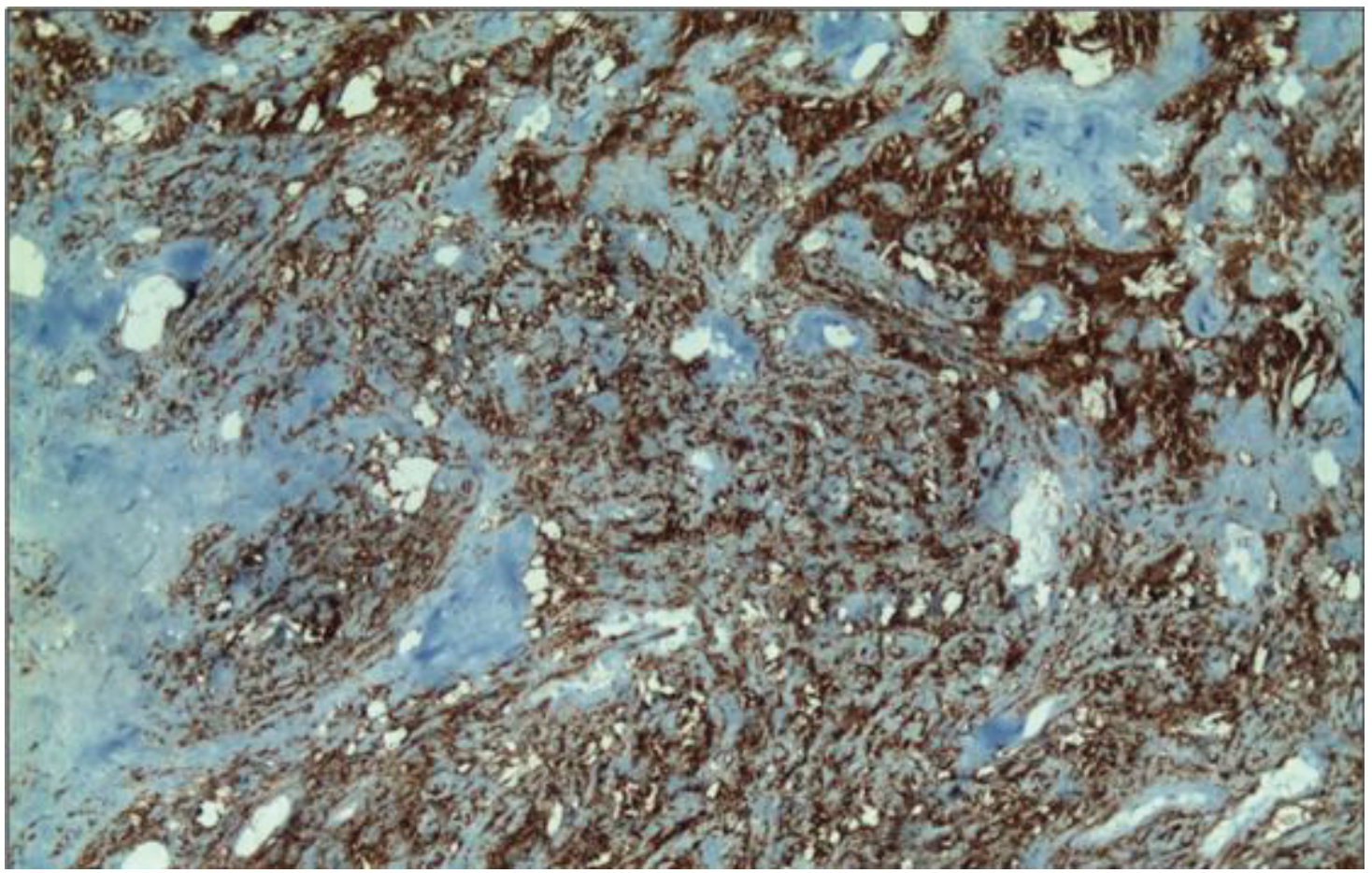

Şekil 4. ER ile tümör hücrelerinde nükleer boyanma (ER; x40)

\section{TARTIȘMA}

Endometrial stromal tümörler uterin korpusun en nadir görülen tümörlerindendir (4). ESN ise endometrial stromal tümörlerin $1 / 4$ kadarını ve uterin tümörlerin $\% 5$ 'ten daha az bir kısmını oluşturur (5). ESN stromal orijinli diğer uterin tümörler gibi peri ve post menopozal dönemde görülür. Tavassoli ve Norris tarafindan yürütülen 60 vakalık çalıșmada ortalama ESN yașı 47 olarak saptanmış (7). Çalışmada spesifik bir klinik presentasyon sergilemeyen ESN olgularinda anemiye neden olabilecek oranda vajinal kanama, pelvik ve abdominal ağr1 en s1k görülen semptomlar olup bunun yanında asemptomatik olgulara da rastlanmıştır (7). ESN olgularında en sık görülen preoperatif tanı leiyomyoma ve adneksial kitle olarak tespit edilmiş $(4,7)$. Oldukça nadir görülen bu antite özellikle küretaj materyallerinde düşük gradeli ESS ile ayırıcı tanıya girmesi açısından önem taşımaktadır (1). ESN ve düşük gradeli ESS'un her ikisinde de vimentin ve CD10 pozitifliği izlenir ve fokal aktin pozitifliği görülebilir. Düşük gradeli ESS'da hemen her zaman ER,PR pozitifliği izlenir (6). Ancak bu olgularda immünhistokimya morfolojik ayrımın yeterli olduğu ESN, ESS ayrımından çok diğer uterin tümörlerden ayrımda yardımcidır.

Endometrial stromal nodülün özellikle küretaj materyallerinde başta düşük gradeli ESS olmak üzere birçok stromal malign tümör ile ayırıcı tanıda ayrımı mümkün olmayabilir (8). Benzer şekilde sellüler leiyomyomlar da soft krem- beyaz kesit yüzüne sahip olmas1, mikroskopik incelemede sellüler olması ve belirgin vaskülarite göstermesi nedeniyle ESN ile ayırıc1 tanıya girebilir. Tipik fasiküler stromal alanların, büyük kalın duvarlı damarların görülmesi ve yaprak benzeri boşlukların varlığı ayırıc1 tanıda yardımc1 olabilecek kriterlerdir (9). ESNde seks cord stromal tümörde izlenen epitelyal benzeri alanların bulunması özellikle de küretaj materyallerinde ayırıcı tanıda sorun yaratabilmektedir ve bu olgularda immünhistokimyasal boyamalar ayırıcı tanıda yardımc1 olamazlar. Tan1 histerektomi materyalinde non-infiltratif sinırların görülmesi ile netleşir (10). Bu tür vakalarda endometrial stromal nodülün ekarte edilemediği raporda vurgulanmalı ve kesin tanının histerektomi materyalinde verilmesinin uygun olacağ1 bildirilmelidir. Ayrıca fokal seks cord like differansiasyon gösteren vakaların relaps ve metastaz gösterebileceği patoloji raporunda bildirilmelidir 


\section{KAYNAKLAR}

1. Marisa R. Nucci, Oliva E. Gynecologic Pathology. A volume in the series Foundations in Diagnostic Pathology. 1st ed. China: 2009; 293-302.

2. F.Z.Fdili Alaoui, H. Chaara, H. Bouguern, M. A. Melhouf, H.Fatemi, A. Belmlih, and A. Amarti. Endometrial Stromal Nodule: Report of a Case. Case Reports in Medicine. 2011 jan. Article ID 260647, doi:10.1155/2011/260647. 5 pages.

3. C. Zaloudek and M.R. Hendricson. (Eds): Mesenchymal tumors of the uterus. In Blaustein's Pathology of the Female Genital Tract. 5th ed., Springer, New York, NY, USA, 2001; 561-615.

4. S.Elagöz, F. Kıvanç, H. Aker. Endometrial Stromal Tumors- a report of 5 cases. Aegean Pathology Jounal, 2005; 2: 140-145.

5. K. Ryuko, K. Takahashi, K. Miyazaki, A case of endometrial stromal nodül, Shimane Journal of Medical Science, 1996; 14: 27-28.

6. M.R. Hendricson, F.A. Tavassoli, R.L. Kempson, et al. Mesenchymal tumors and related lesions. In World Health Organization Classification of Tumours. Tumors of the Breast and Female Genital Organs. Fattaneh A. Tavassoli, Peter Devilee (Eds). IARC Press: Lyon 2003; 233-244

7. K. R. Kim, S. Y. Jun, I. A. Park, et al. Endometrial Stromal tumor with limited infiltration and probable extrauterine metastasis: report of a case. Annals of Diagnostic Pathology, 2005; 9: 57-60.

8. Lamboley JL, Crambert A, Le Moigne F, et al. A rare tumor: endometrial stromal nodule. J Radiol. 2010; 11:1161-1163.

9. Baker P, Oliva E. Endometrial stromal tumours of the uterus: a practical approach using conventional morphology and ancillary techniques. I Clin Pathol 2007; 235-43.

10. K. L. Chang, G.S. Crabtree, S. K. LimTan, et al. Primary uterine endometrial stromal neoplasms. A clinicopathologic study of 117 cases. American Journal of Surgical Pathology, 1990; 14: 415-438. 
